\title{
Propagation of short period (10-40 min) atmospheric gravity waves from troposphere to mesosphere over Gadanki, India
}

\author{
S.C. Chakravarty, Kamsali Nagaraja* \\ Department of Physics, Bangalore University, Bangalore 560056, India
}

\section{A R T I C L E I N F O}

\section{Article history:}

Received 23 December 2014

Received in revised form

16 July 2015

Accepted 17 July 2015

Available online 18 July 2015

Keywords:

Atmospheric gravity waves

Turbulence

MST radar

Tropical troposphere/mesosphere

\begin{abstract}
A B S T R A C T
The Indian MST radar at Gadanki $\left(13.5^{\circ} \mathrm{N}, 79.2^{\circ} \mathrm{E}\right)$ has been utilised to conduct a detailed study of the close coupling between the troposphere and the mesosphere through the vertically propagating atmospheric gravity waves. For this purpose two cases from a special campaign dedicated to the simultaneous measurement of the fluctuations in the UTLS (Upper Troposphere and Lower Stratosphere) and in the mesosphere during 2001 and one case from a follow up observation in 2002 have been investigated. By using both the FFT and wavelet techniques, the near simultaneous tropospheric and mesospheric data of radar return signal strengths and tropospheric wind fields are analysed. The signatures of relatively high frequency gravity waves with periods between $\sim 10$ and 40 min have been clearly traced as propagating waves from the tropospheric turbulent layer heights $(\sim 8-18 \mathrm{~km})$ to the lower mesospheric heights (65$80 \mathrm{~km}$ ). Significant peak correlation coefficients of 0.56 and 0.45 have been found between the SNR time series of pairs of troposphere and mesosphere levels indicating the propagation of high speed gravity waves. The time series of wavelet spectra determined for the tropospheric SNR/zonal winds and the mesospheric SNR show that the detectability of the gravity waves increases at mesospheric heights. It is shown that the continuous SNR values received from the mesosphere can be used as an effective parameter for studies featuring mesospheric wave dynamics. Based on the observed values of vertical wavelengths and wave amplitudes, the horizontal wavelengths, wave phase and group velocities have been estimated for different wave periods. These results have implications on monitoring of the ubiquitous atmospheric gravity waves generated mainly by the tropospheric weather system of the tropical region from their imprint on the mesospheric turbulence structures.
\end{abstract}

(c) 2015 Elsevier Ltd. All rights reserved.

\section{Introduction}

The Mesosphere, Stratosphere, Troposphere (MST) radar, also called the Gadanki radar has been operating at Gadanki $\left(13.5^{\circ} \mathrm{N}\right.$, $79.2^{\circ} \mathrm{E}$ ), India since 1992 . The main purpose of the facility is to carry out high spatial and temporal resolution observations of vertical wind profiles and waves in the height range of $\sim 5-100 \mathrm{~km}$ (except for the gap between $\sim 30$ and $60 \mathrm{~km}$ due to poor radar reflectivity from this region). The present radar transmission peak power of 2.5 MW is particularly helpful to probe the mesosphere (50-85 km) at sufficient temporal resolution to resolve the vertical propagation of atmospheric gravity waves from the troposphere to the mesosphere at one location. This would not be possible by using space based systems like satellites, rockets and balloons. Detailed specifications of this radar, methods of extraction of return echo power levels or SNR,

\footnotetext{
* Corresponding author. Fax: +91 8023219295

E-mail addresses: chakravarty08@gmail.com, kamsalinagaraj@gmail.com (K. Nagaraja).
}

Doppler shifts/widths etc., and results from investigations pursued to characterise the broad dynamical state of the tropical mesosphere have been reported earlier (Rao et al., 1995, Datta et al., 2001; Chakravarty and Datta, 2007). Such advanced radars are functional only at a few more locations in the middle and high latitude regions (e.g., Kubo et al., 1997, Lee et al., 2014, Chilson et al., 1999).

The Gadanki radar operates at $53 \mathrm{MHz}$ and the return echoes are caused by the coherent scatter from the neutral air turbulence driven radar refractive index fluctuations of $3 \mathrm{~m}$ scale size irregularities (Balsley and Gage, 1980). While in the mesosphere (or the D-region ionosphere) turbulence governed electron density irregularities produce the backscattered signal, in the troposphere and lower stratosphere it is from similar variations of water vapour and temperature respectively (Röttger, 1980).

The Gadanki radar has been extensively utilised to carry out investigation of troposphere, E- and F-region ionosphere (e.g., Das et al., 2008, Patra et al., 1997). In comparison the mesospheric investigations are only a few dealing mainly with the morphology of radar backscatter echoes, line of sight velocity fields and the fine 


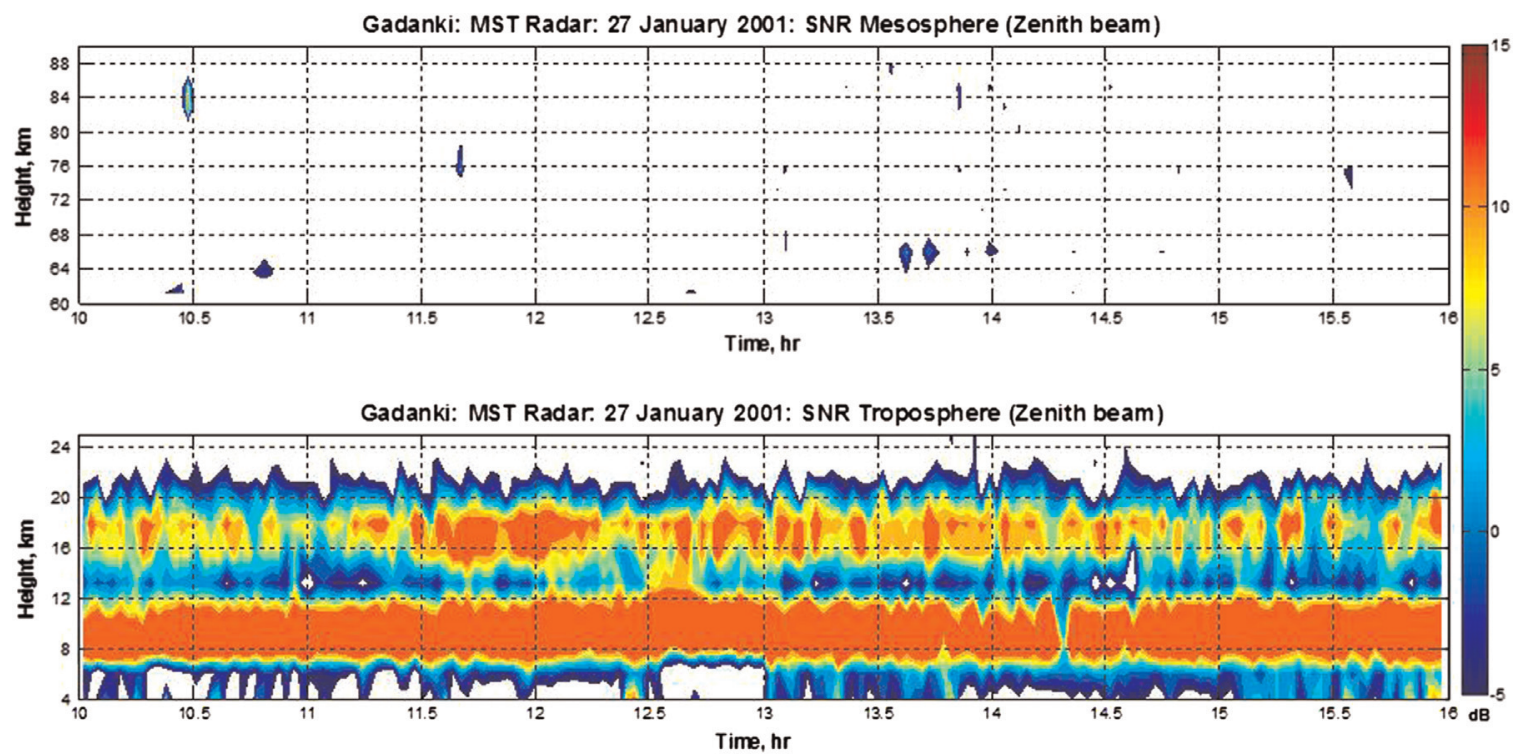

Fig. 1. SNR contours for the zenith beam on 27 January 2001.

structure of the horizontally stratified scattering layers (Kamala et al., 2003; Chakravarty et al., 2004). Recently some preliminary studies have been carried out indicating possible links of the vertically propagating atmospheric gravity waves between the troposphere and the mesosphere by using the Gadanki radar (Chakravarty, 2012) and in combination with wave signatures in airglow emissions (Pramitha et al., 2015).

So far, most of the radar studies related to gravity waves deal with observations taken either in the Upper Troposphere and Lower Stratosphere (UTLS) region or in the mesospheric region separately. Measurements with near simultaneous and continuous observations covering these two regions are very rare. According to the comprehensive review of this field by Fritts and Alexander, 2003 tropospheric gravity wave propagation studies have been carried out only from the middle latitude station of the MU radar in Kyoto. Tsuda (2014) has recently summarised the altitude profiles of gravity wave amplitudes from troposphere to mesosphere using the MU radar and GPS radio occultation observations. The main purpose of this paper is to study the generation of gravity waves in the troposphere, their vertical propagation and detection in the mesosphere as evidenced by the special observations over Gadanki, a low latitude station.

\section{Data and method of analysis}

The Doppler spectra as a function of time and height are obtained as the primary raw data from the radar observations. These are converted into low order moments using the special software called the Atmospheric Data Processor (ADP) which uses an adaptive spectral moments estimation technique to provide the atmospheric parameters like the return echo power/SNR, line of sight velocities and the spectral width (signifying the magnitude of turbulence) with maximum height coverage (Anandan et al., 2005). From multi-beam data for vertical and off vertical positions (usually $10^{\circ}$ off zenith), the zonal $(u)$, meridional $(v)$ and vertical velocities $(w)$ can be determined using the ADP, provided the radar has near simultaneous and continuous SNR in at least 3 beam directions within the same radar scan cycle. It is well known that this condition is generally well satisfied in the troposphere but not in the mesosphere due to intermittent and inhomogeneous nature of the distribution of scattering centres and lack of signal correlation between the radar beams within the same scan. The time series data of SNR, $u, v$ and $w$ are analysed to derive the wave periodicities using both power spectrum (i.e., FFT) and wavelet analyses to ensure the dominant wave periods/power and its variation in space and time.

In order to study the characteristics of the coupling between troposphere and mesosphere dynamics, near simultaneous data of the two regions was collected during the year 2001 under a proposal by one of the authors. Since this required the radar to work with its full capacity of duty cycle/power to cover both the regions, such data could be collected only for 3-4 days a month. In May, June and December of 2001 these data were not collected since the radar operation was affected by maintenance. During this period, the radar was operated in multi beam mode with a time resolution of about $50 \mathrm{~s}$ and a spatial resolution varying from 1.2 to $2.4 \mathrm{~km}$. Based on the moments data, the ADP software is used for RTI (Range Time Intensity) plots pertaining to all the beam directions taken together. Under the present study to check the overall data availability for the gravity wave propagation studies, first the multi beam RTI plots of SNR for each day (total being 35 days of data collected during 2001) are examined and then analysis is carried out to separate the radar parameters for individual beam directions. The vertical beam direction SNR contour plots for troposphere and mesosphere using a single scale of values from -5 to $15 \mathrm{~dB}$ are plotted for all the days. Following this criterion, about $50 \%$ of the days does not show any significant mesospheric echoes. Also, if there are some mesospheric echoes on certain days, periodic breaks in the data collection affected the selection process. For example, Fig. 1 shows the SNR contours for the vertical beam on 27 January 2001 using this filtering method. It can be seen that the mesospheric echoes are almost non-existent and hence cannot be used for our studies. Finally, we could select only 2-days of data which had good mesospheric and tropospheric echoes. Appendix 1 provides a tabulated list of the days and periods of observation along with the volume of data collected and the status regarding the availability of the mesospheric echoes. In a very limited way such simultaneous data were collected during the year 2002 but only for 3 days in June. Out of these 3-days, the data on 25 June 2002 could be selected with a spatial resolution of $1.2 \mathrm{~km}$ for a short period. Table 1 gives the details of the observational data selected for the present study. While the data on 25 June 2002 has mainly been used to derive the gravity wave propagation and 
Table 1

Details of MST radar observation data used for the present study.

\begin{tabular}{|c|c|c|c|c|c|}
\hline $\begin{array}{l}\text { Date of } \\
\text { observation }\end{array}$ & $\begin{array}{l}\text { Time of ob- } \\
\text { servation } \\
\text { (h) }\end{array}$ & $\begin{array}{l}\text { Height } \\
\text { coverage } \\
(\mathrm{km})\end{array}$ & $\begin{array}{l}\text { Time re- } \\
\text { solution } \\
\text { (sec) }\end{array}$ & $\begin{array}{l}\text { Height re- } \\
\text { solution } \\
(\mathrm{km})\end{array}$ & $\begin{array}{l}\text { Measured } \\
\text { parameters }\end{array}$ \\
\hline $\begin{array}{l}19 \text { November } \\
2001\end{array}$ & $1148-1312$ & $3.6-85.2$ & 50 & 1.2 & $\begin{array}{l}\text { SNR }(Z- \\
\text { beam) }\end{array}$ \\
\hline \multirow[t]{2}{*}{26 July 2001} & \multirow[t]{2}{*}{ 1018-1142 } & $3.6-85.2$ & 5 & 2.4 & $\begin{array}{l}\text { SNR (Z- } \\
\text { beam) }\end{array}$ \\
\hline & & $3.6-20.4$ & 100 & 2.4 & $\mathrm{U}, \mathrm{V}, \mathrm{W}$ \\
\hline \multirow[t]{2}{*}{25 June 2002} & \multirow[t]{2}{*}{$1024-1148$} & $3.6-90$ & 50 & 1.2 & SNR \\
\hline & & $3.6-25.2$ & 50 & 1.2 & $\begin{array}{l}\text { (E W N S Z } \\
\text { beams) } \\
\mathrm{U}, \mathrm{V}, \mathrm{W}\end{array}$ \\
\hline
\end{tabular}

characteristics, the results of the other two days, viz., 19 November 2001 and 26 July 2001 have been included for the purpose of comparison.

\section{Results}

In order to get an overview of the observations during 25 June 2002, a contour plot of SNR (with time as $x$-axis and height as $y$ axis) for radar vertical beam is shown in Fig. 2 for the troposphere and the mesosphere, i.e., between $4-20 \mathrm{~km}$ and $67-78 \mathrm{~km}$ respectively. The intervening height range of $20-66 \mathrm{~km}$ does not have any significant backscattered radar echo and hence it is not included in the contour plot. A common signal power scale of -5 to $15 \mathrm{~dB}$ has been used for both the contours which clearly show that the signal strengths received from the mesosphere are weak by a factor of 4-5 compared to that from the troposphere. The scattering regions are formed in horizontally stratified layers of thickness $\sim 4 \mathrm{~km}$ in troposphere and $\sim 2 \mathrm{~km}$ in the mesosphere. These are layers where the turbulence refractive index variation is responsible for radar signal return echo. There are 3 distinct and strong scattering layers in the troposphere, two of these below $12 \mathrm{~km}$ altitude and one near the tropopause level (normally $\sim 18 \mathrm{~km}$ over Gadanki). In the mesosphere there are two clear scattering layers one at $\sim 70 \mathrm{~km}$ and the other $\sim 76 \mathrm{~km}$. While the SNR time series shows specific layering due to presence of high turbulence, the structures within the thick layers have identifiable patterns as the scatter producing tracers (mentioned earlier) resonate with wave induced disturbances in addition to being transported by the background wind. A point to be noted is that there is a close correspondence between these induced shapes of turbulent patterns in tropopause with those in the mesospheric layers as shown by arrows and lines in the figure (there is a break in signal values between height regions 20$67 \mathrm{~km}$ ). Tracing these similar patterns from tropopause to higher layers, the time delay of about 10-15 min between the tropopause and the lower mesospheric layer indicates possible coupling between the two regions due to the relatively high speed gravity wave perturbations. Similarly there is a time delay between the lower and the middle mesosphere turbulent structures. The mean vertical distance from the tropopause layer to the first mesospheric layer is $\sim 50 \mathrm{~km}$ and between the two mesospheric layers is $\sim 6 \mathrm{~km}$.

Similar contour diagrams of SNR data for 19 November 2001 and 26 July 2001 are plotted in Fig. 3. Basic characteristics are similar with coupling seen between the tropospheric turbulence structures around $9 \mathrm{~km}$ and the mesospheric scattering patterns around $69 \mathrm{~km}$ and $75 \mathrm{~km}$ for 19th November. While during 26 July 2001, the mesospheric structures can be traced to the tropospheric signal variations around $14 \mathrm{~km}$, this link cannot be easily discerned due to the existence of very strong turbulence.

Apart from the SNR values from the radar beam in the vertical direction, the observations also provide the return echoes by pointing the radar beam towards West, South, East and North (WSEN) directions at $10^{\circ}$ zenith angle. The backscattered signals received from these directions help in determining the filling factor of the radar volume formed by the radar beam angle of $3^{\circ}$ and the vertical extent of range bins. Figs. 4 and 5 show the SNR contours in the W/S and E/N beam directions for 25 June 2002 (see Fig. 2 for the vertical beam on the same date). It can be noted that while the south and west beams have more signal strengths compared to the east and north beams for the mesospheric heights, this difference is absent for the tropospheric heights due

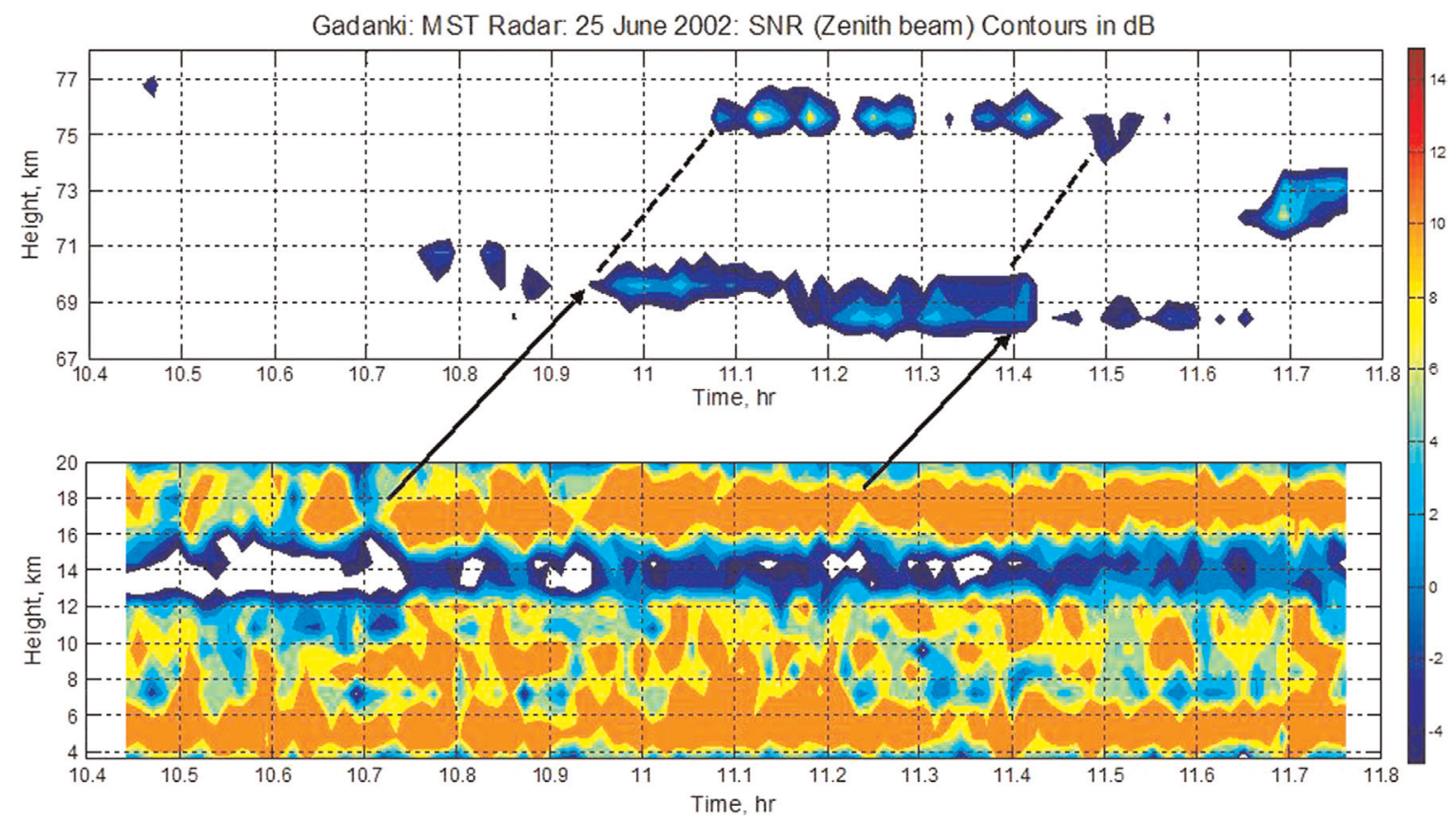

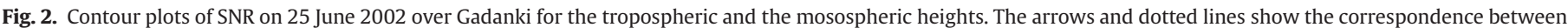
the pattern of the SNR between tropopause-lower mesosphere and between the two levels in the mesosphere indicating possible coupling through waves. 

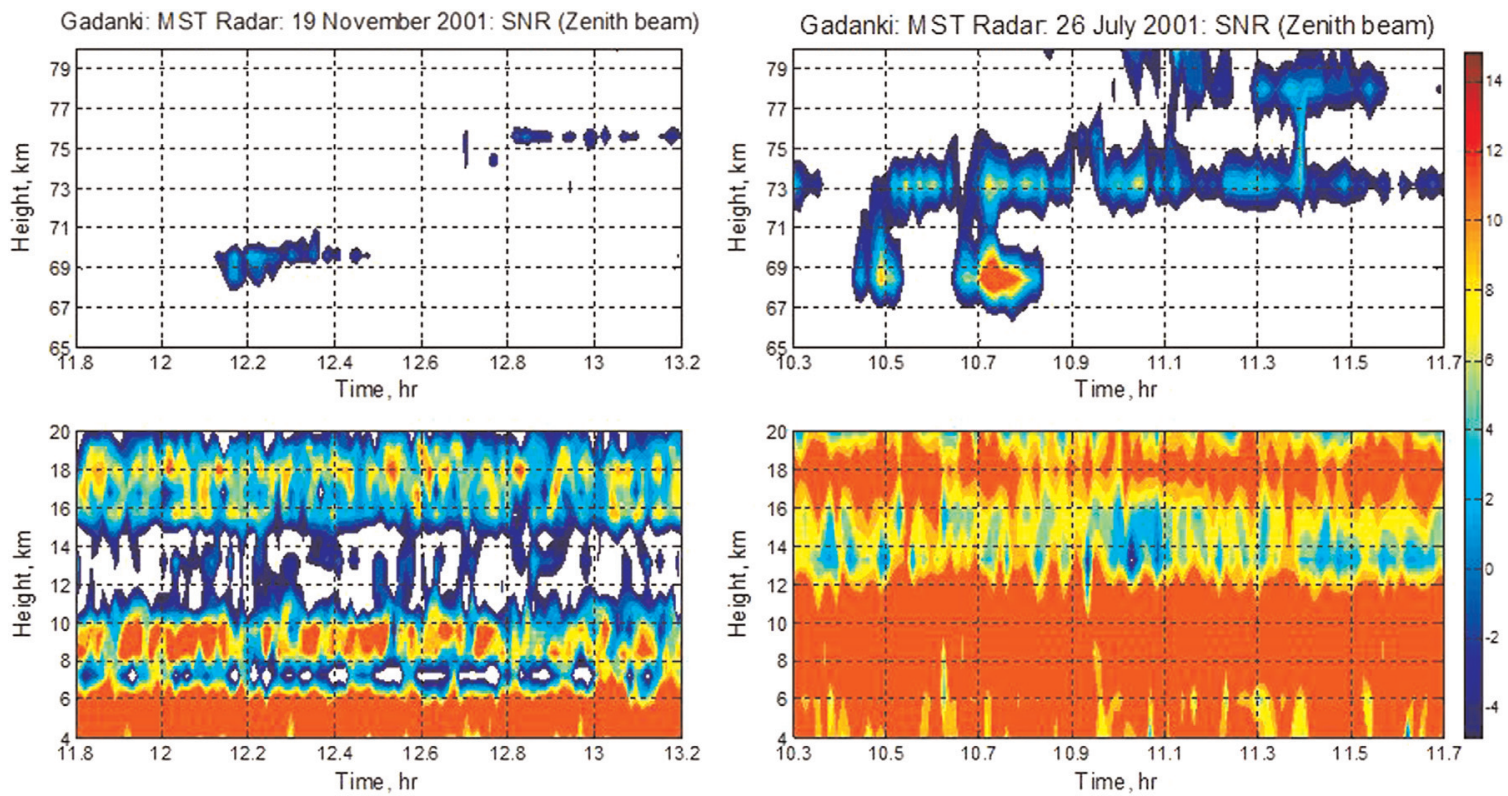

Fig. 3. SNR contour plots for 19 November and 26 July 2001 for the troposphere and the mesosphere.

to the homogeneous nature of turbulence there. Hence it is inferred that the scattering centres were more populous between the vertical and $10^{\circ}$ off vertical towards south-west direction indicating an asymmetry in the distribution of scattering centres in the mesosphere. Similarly the tropopause structures are well correlated with the mesosphere for $\mathrm{S} / \mathrm{W}$ beams as compared to the $\mathrm{N} / \mathrm{E}$ beams which means that due to asymmetry the details are not equally captured by the radar in the mesosphere for different beam directions at $10^{\circ}$ zenith angle.

To evaluate and quantify the result of correspondence between SNR values of certain heights in the troposphere and mesosphere mentioned earlier, a correlation analysis has been carried out between SNR values at individual heights of troposphere and mesosphere by progressively advancing the time axis for the tropospheric values by $100 \mathrm{~s}$. Fig. 6 shows the SNR time series at individual heights in the troposphere and mesosphere and Fig. 7, the plots of correlation coefficients between pairs of SNRs at tropospheric and mesospheric levels for 25 June 2002. It can be seen that the mesospheric SNRs at 68.4 and $75.6 \mathrm{~km}$ are better correlated with the $18 \mathrm{~km}$ SNR near local tropopause with correlation coefficients reaching maximum values of 0.56 and 0.45 , with a time shift of $600 \mathrm{~s}$ and $400 \mathrm{~s}$, respectively. However, these time differences cannot be directly used to compute the gravity wave phase/group velocities, as for example the correlation between SNRs at $18 \mathrm{~km}$ and $67.2 \mathrm{~km}$ drops drastically (maximum value being 0.2 ) compared to those between $18 \mathrm{~km}$ and $68.4 \mathrm{~km}$ (with maximum value being 0.56 ) possibly due to mesospheric turbulent layer's downward motion and other mesospheric dynamical processes.

Fig. 8 shows the broad contour plots of zonal $(u)$, meridional $(v)$ and vertical velocities $(w)$ between the height ranges of 4-20 km during the same 90 min period of 25 June 2002 to match the SNR plots in Fig. 2. The first panel shows that the lower troposphere up to about $8 \mathrm{~km}$ has small positive values (weak westerly zonal
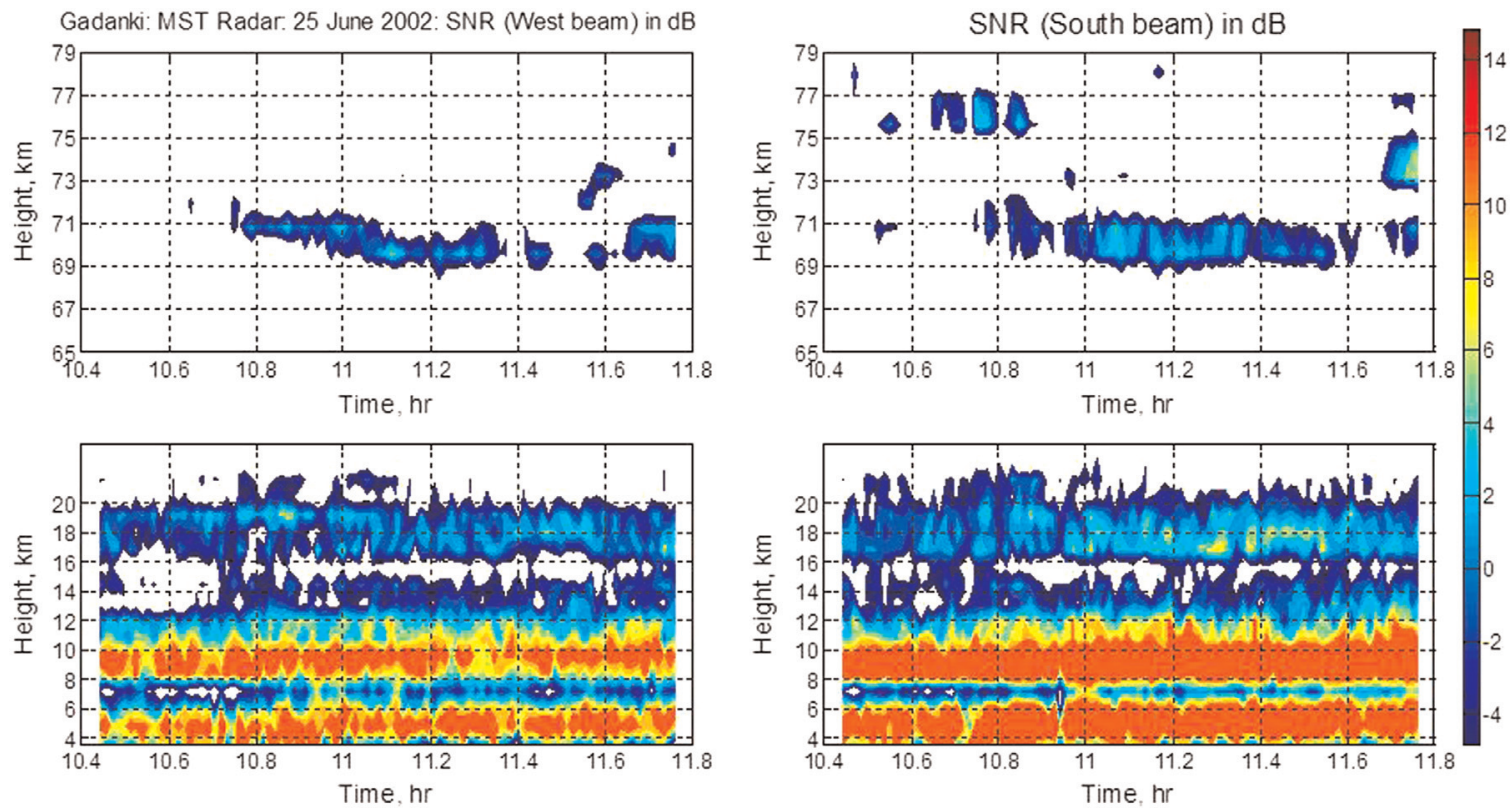

Fig. 4. Contours of SNR (in dB) on 25 June 2002 for the West and South beam directions. 

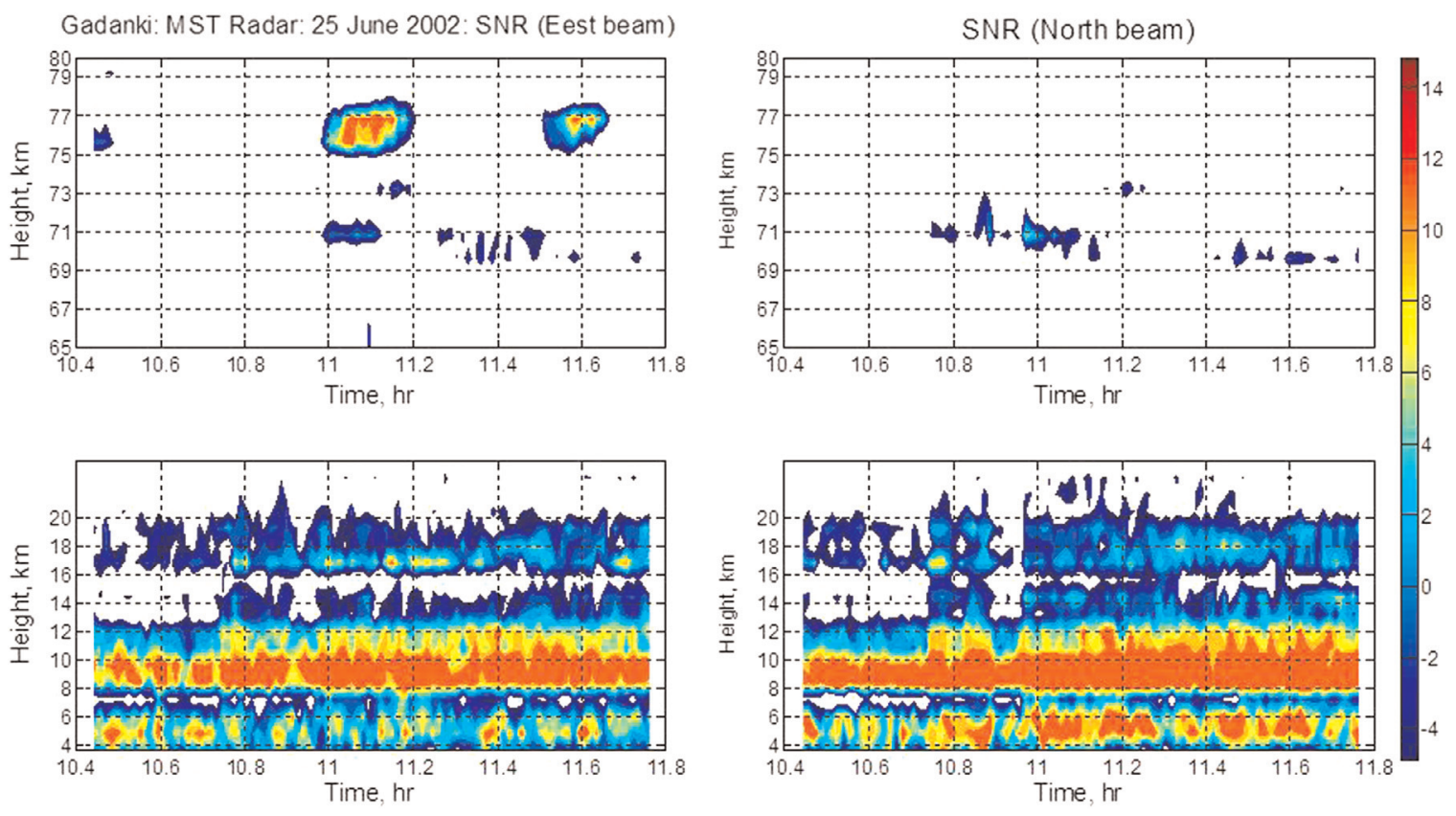

Fig. 5. Contours of SNR (in dB) on 25 June 2002 for the East and North beams.

winds) which gradually get reversed around the height of $10 \mathrm{~km}$ and become strong easterly winds (large negative values) around $16-17 \mathrm{~km}$. Similarly in the second panel, the meridional winds are very weak southerlies up to about $10 \mathrm{~km}$ but higher up become strong northerly winds (large negative values). Third panel is the plot of vertical velocity contours with fluctuating negative/downward and positive/upward values. The vertical velocity peak values are one order of magnitude lower than the horizontal velocity components and there is no major change in the magnitude of vertical winds with height.

In order to explore the presence of short period gravity waves, the time series of $250 \mathrm{~s}$ average values of $\mathrm{u}, \mathrm{v}$ and $\mathrm{w}$ data of 25 June 2002 are subjected to Fast Fourier Transform (FFT) analysis with digital band pass filtering for separating dominant frequencies at specific heights of turbulent layers at 8, 13 and $18 \mathrm{~km}$. While the $10 \mathrm{~min}$ period is estimated to be the highest limit of the BV frequency considering the entire tropospheric height range, the upper limit of the period of $40 \mathrm{~min}$ is based on the Nyquist frequency consideration. The periodograms are plotted for zonal, meridional and vertical wind time series data of 25 June 2002 and shown in Fig. 9. It can be noted that there is considerable power in waves of periodicities between two groups i.e., 10$20 \mathrm{~min}$ and $20-40 \mathrm{~min}$. For zonal as well as meridional winds the amplitudes of the waves increase from minimum values at $8 \mathrm{~km}$ and maximum between 13 and $18 \mathrm{~km}$. For meridional winds the waves between 30 and $40 \mathrm{~min}$ periods are more pronounced compared to those in the 10-20 min group. The power of the wave spectrum in the vertical winds is lower than those seen in zonal or
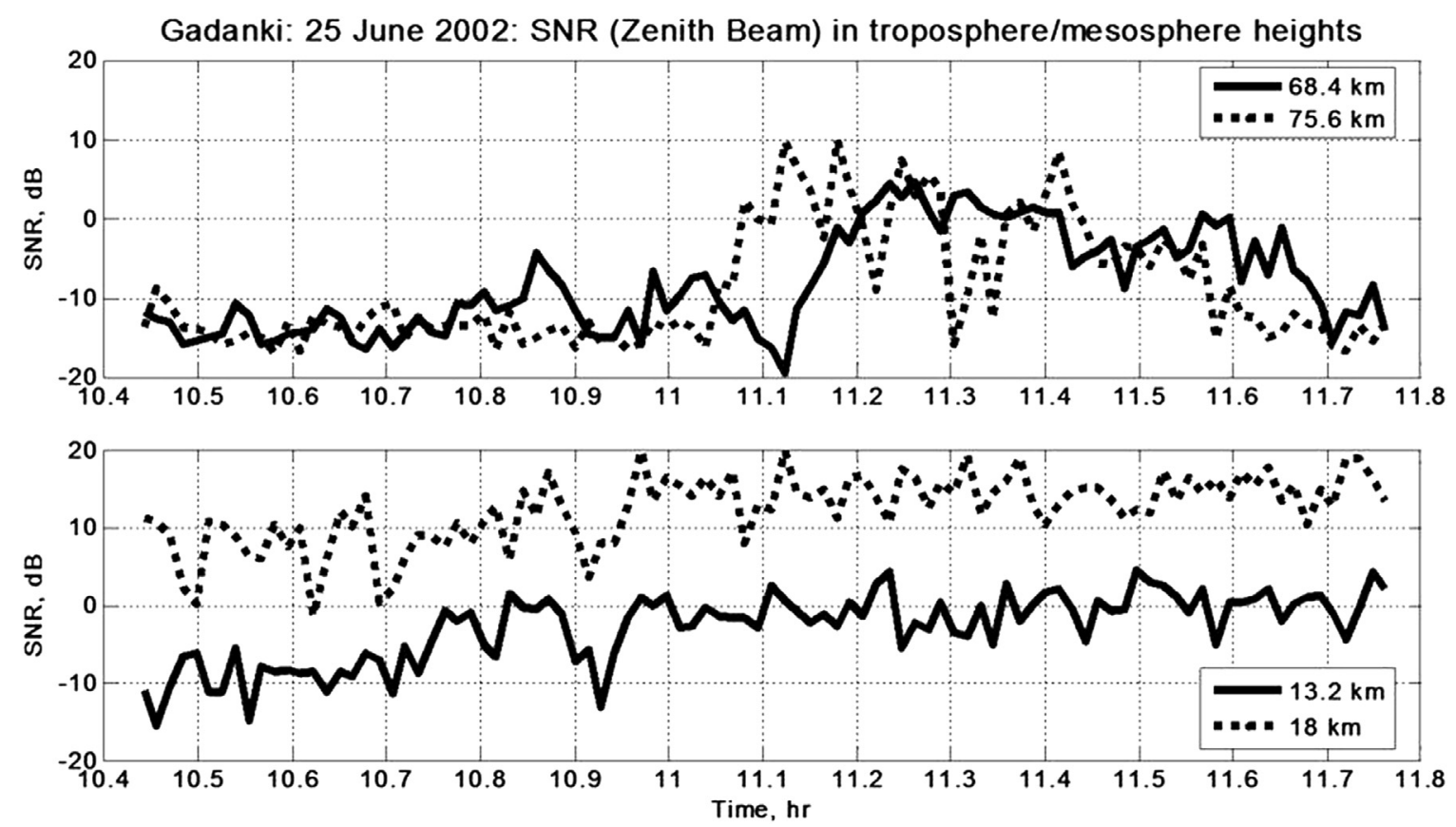

Fig. 6. SNR time series at individual heights in the troposphere and mesosphere on 25 June 2002. 


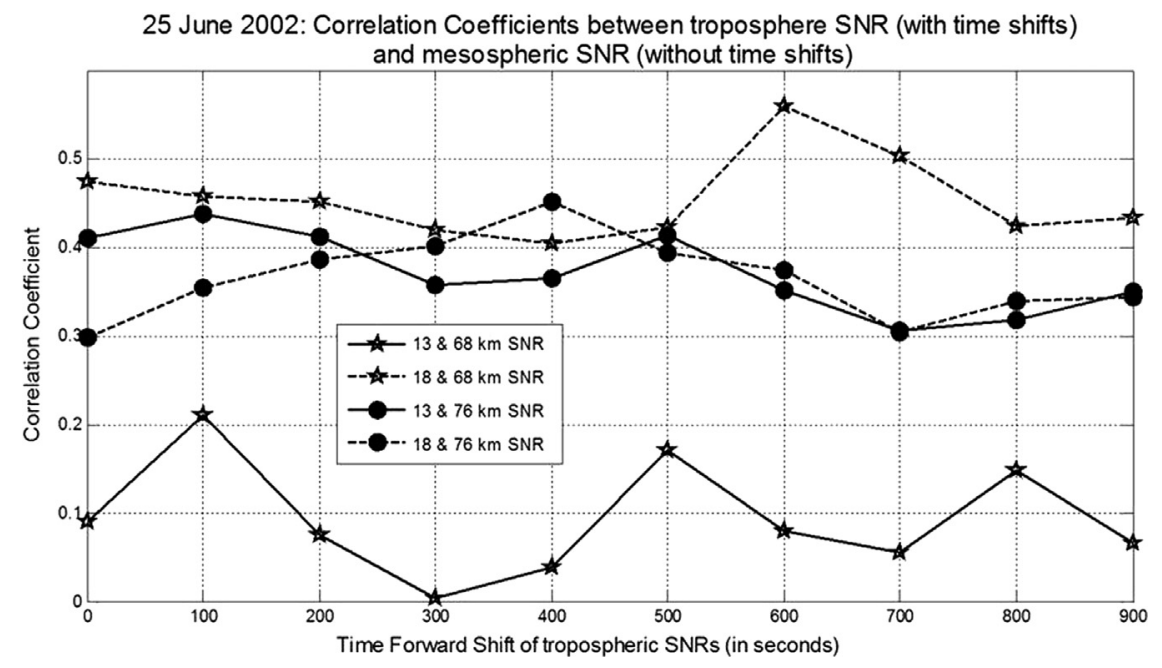

Fig. 7. Plots of correlation coefficients between sets of SNRs at tropospheric and mesospheric levels on 25 June 2002.

meridional winds.

Similar results for 26 July 2001 comprising the velocity plots and the periodograms at specific tropospheric heights are given in Figs. 10 and 11 respectively. The wind velocity contours show dominant easterlies and alternating weak southerlies/strong northerlies around tropopause level. The contours of zonal winds show clear wave type features in velocity fields around tropopause heights. The vertical winds are of the same order as obtained on 25 June 2002 but the height profile shows a dominant downward motion in the lower troposphere and upward in the upper troposphere. The power spectra at 13 and $18 \mathrm{~km}$ show similar trends but have many peaks within the wave periods of 10-40 min.

While power spectra provides the relative strengths of waves with different periodicities present in the entire time series of zonal velocities at different heights, the wavelet analysis provides information on the time variation of the amplitude spectra of these waves. The results of such wavelet analysis carried out for u, $\mathrm{v}$ and $\mathrm{w}$ time series of 25 June 2002 are shown in Fig. 12. The contours are the plots of wavelet coefficients (with respect to time and wave periods) of the wind components at a fixed height of
$18 \mathrm{~km}$. From the figure it is clear that the values of wavelet coefficients are comparable for zonal and meridional winds. The values of coefficients for the wavelets of vertical winds are about a factor of 5-6 lower in magnitude compared to those of the zonal and meridional winds. It is also seen that waves of different periods occur at different times but the underlying trends in all the three spectra show high degree of correlation.

To determine the role played by the propagating gravity waves in formation/growth of mesospheric turbulent structures, two sets of plots one for 25 June 2002 (first column) and the other for 26 July 2001 (second column) are shown in Fig. 13. The first row of panels shows the SNR contour plots with stronger echoes on 26 July 2001 which generally matches with stronger zonal winds (easterlies) in second row and higher values of wavelet coefficients in the third row. Taking into account some time delays of wave propagation between tropopause to mesosphere, it can be seen that the gravity waves with periods between 10 and $40 \mathrm{~min}$ are able to propagate up to the mesospheric heights with a good correlation with the gravity wave intensities in the tropopause level.
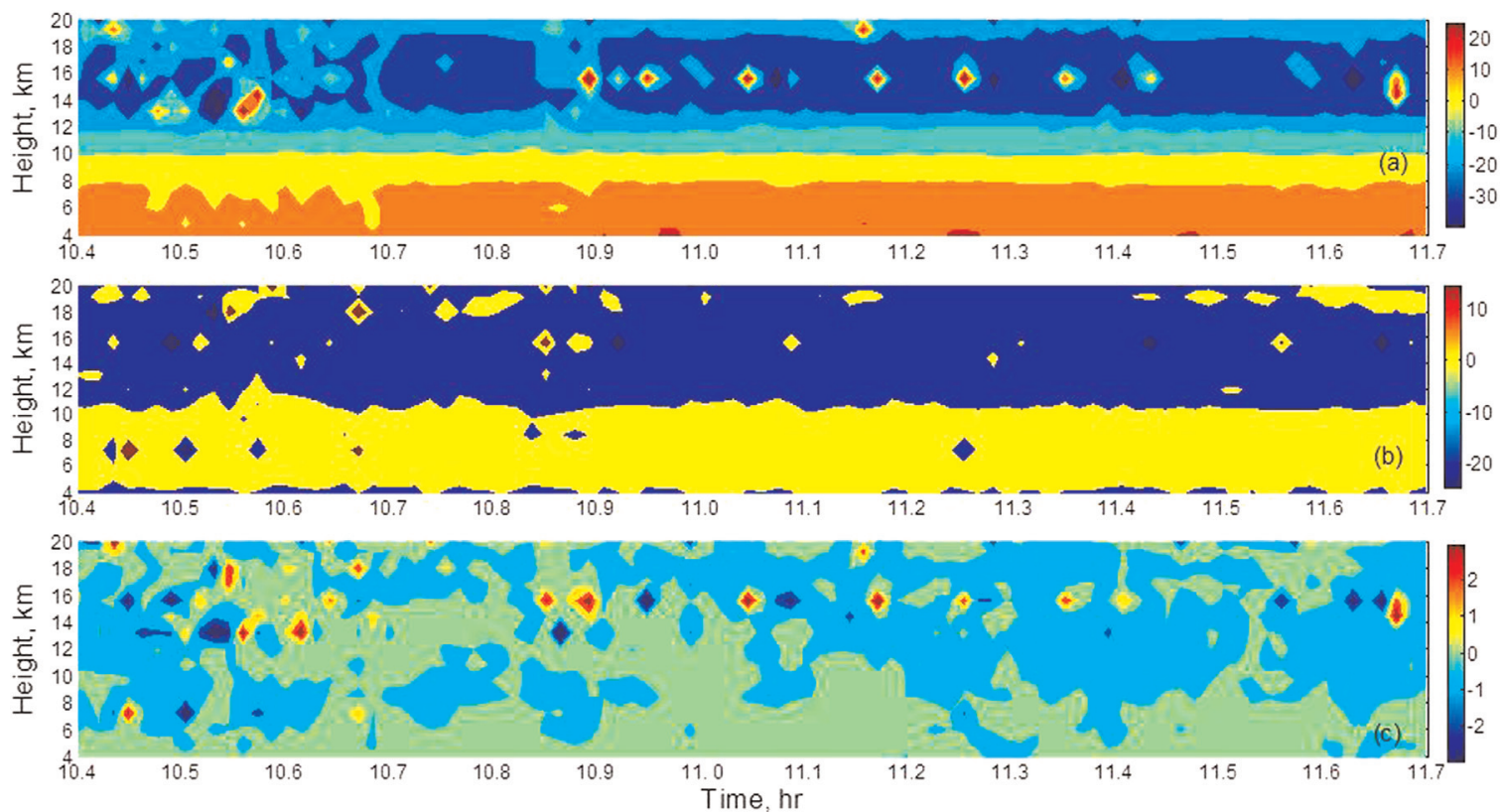

Fig. 8. Contours of (top to bottom panel) zonal $(u)$, meridional $(v)$ and vertical $(w)$ wind velocities in the troposphere on 25 June 2002. 
Gadanki, 25 June 2002: Periodograms of 4.2 min mean velocities
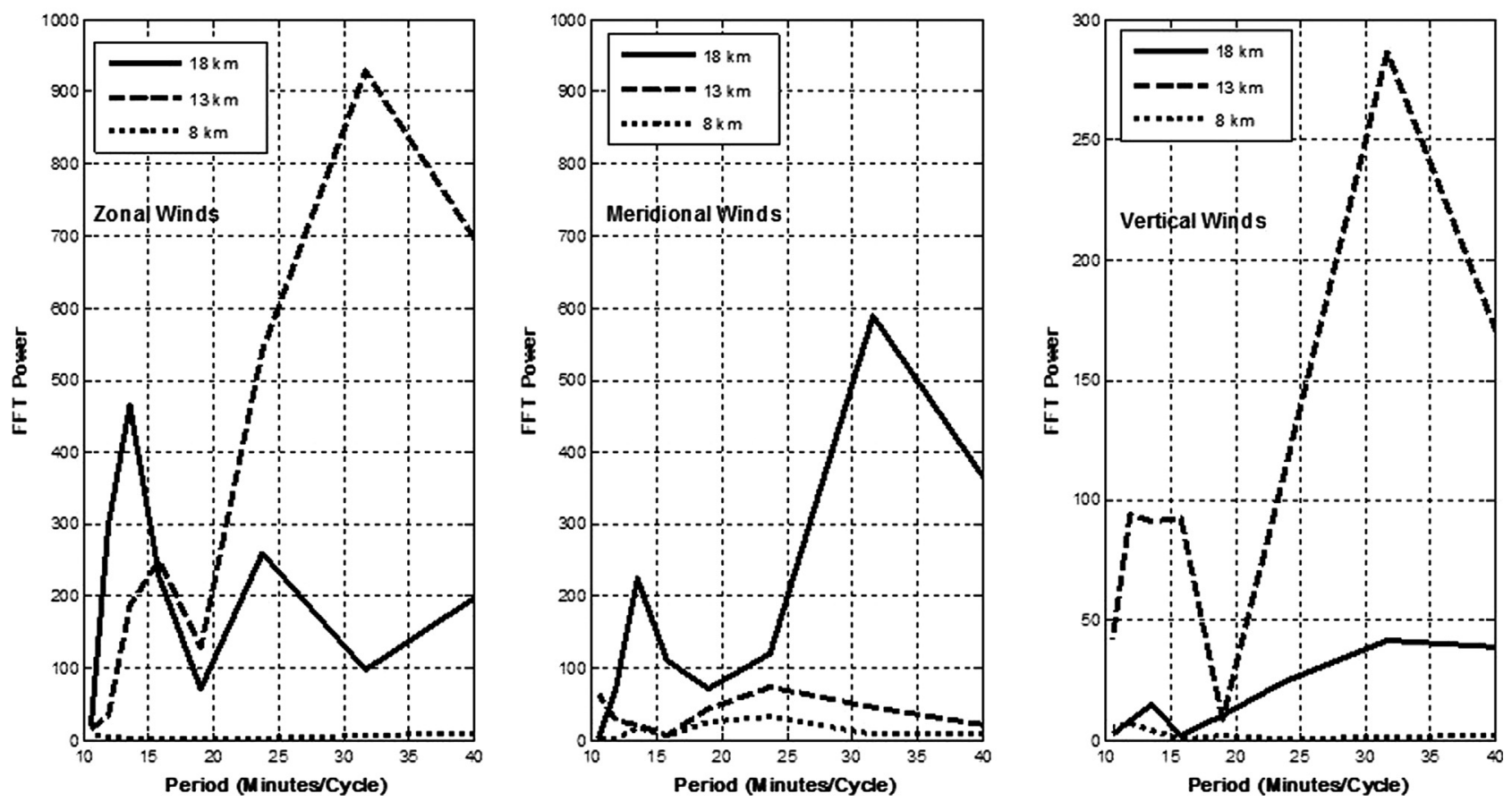

Fig. 9. Plots of periodograms for $u, v, w$ at specific tropospheric heights of 8, 13 and $18 \mathrm{~km}$ on 25 June 2002.

Taking the results of wavelet spectra for 25 June 2002 together, Fig. 14 shows very clear development of the gravity wave intensities with time and with respect to its spectra corresponding to wave periods between $10-40 \mathrm{~min}$. The gravity waves are detectable at tropopause altitude of $18 \mathrm{~km}$. While propagating up these waves reach the mesosphere and their intensity increases with a time delay as evidenced from the wavelet in SNR at $68 \mathrm{~km}$. Unlike the SNR at $68 \mathrm{~km}$, the wave impressions are not so clearly visible in the wavelets of SNR at $18 \mathrm{~km}$. This result on the direct link between gravity waves and their clear detection in the mesosphere has potentials to further explore the role of tropospheric weather sources to wave forcing by observing near simultaneous radar data of the troposphere and the mesosphere in common radar scans.

The calculations of wave parameters of the gravity waves have been carried out from the dispersion relation and related expressions. The main approach has been to derive the range of vertical wavelengths from height profiles of velocity components (not shown here) and the wave amplitudes for the zonal and vertical velocities near the tropopause height from Fourier spectra. It is found that the vertical wavelengths of the gravity waves vary between 5 and $20 \mathrm{~km}$ and their wave amplitudes $10-20 \mathrm{~m} / \mathrm{s}$ for the zonal wind component $\left(\mathrm{u}^{\prime}\right)$ and average vertical component $\left(\mathrm{w}^{\prime}\right)$ of $1.2 \mathrm{~m} / \mathrm{s}$. The examples of horizontal wavelength values
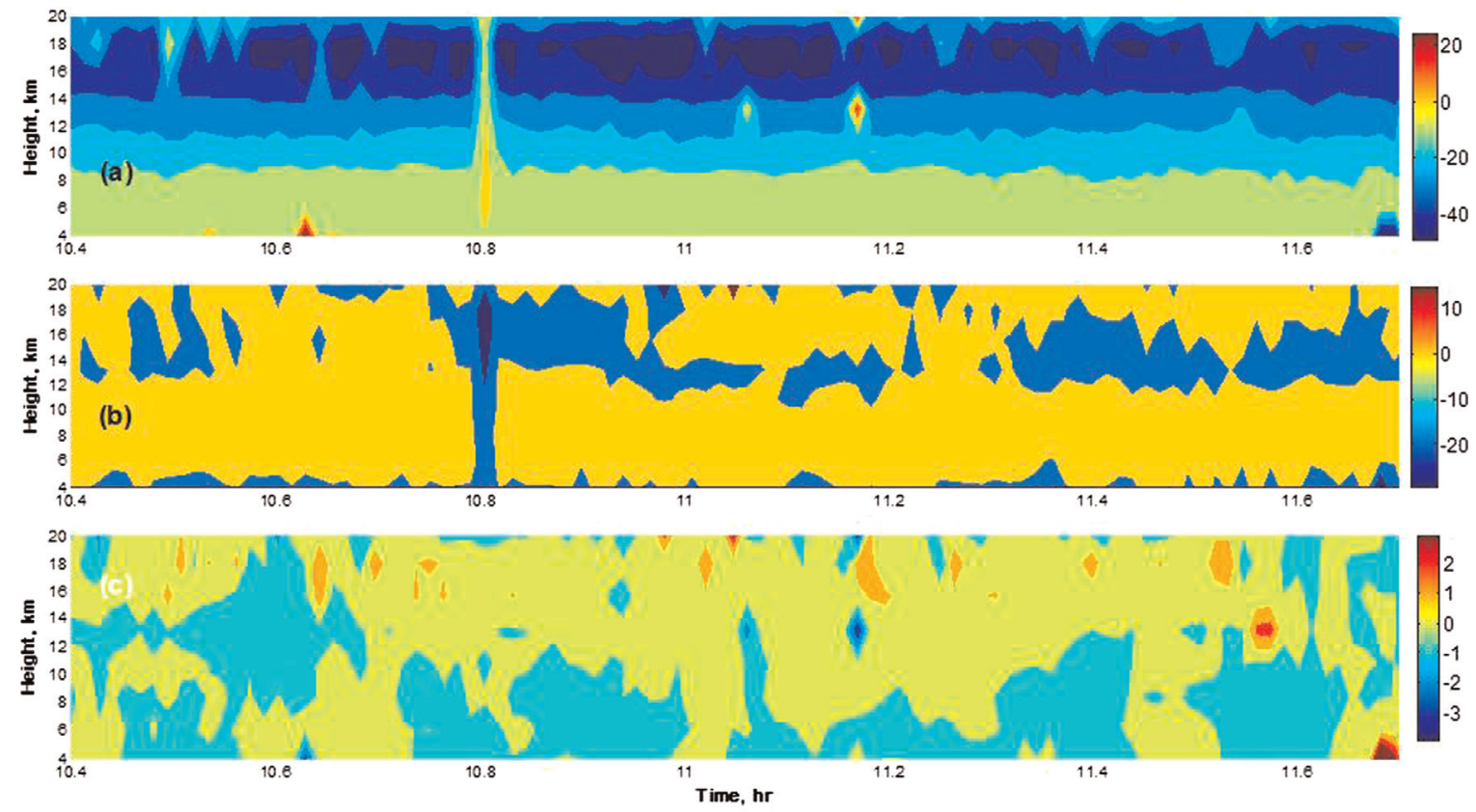

Fig. 10. Contour plots of $u, v, \mathrm{w}$ on 26 July 2001. (a) zonal, (b) meridional and (c) vertical velocity (m/s) contours. 

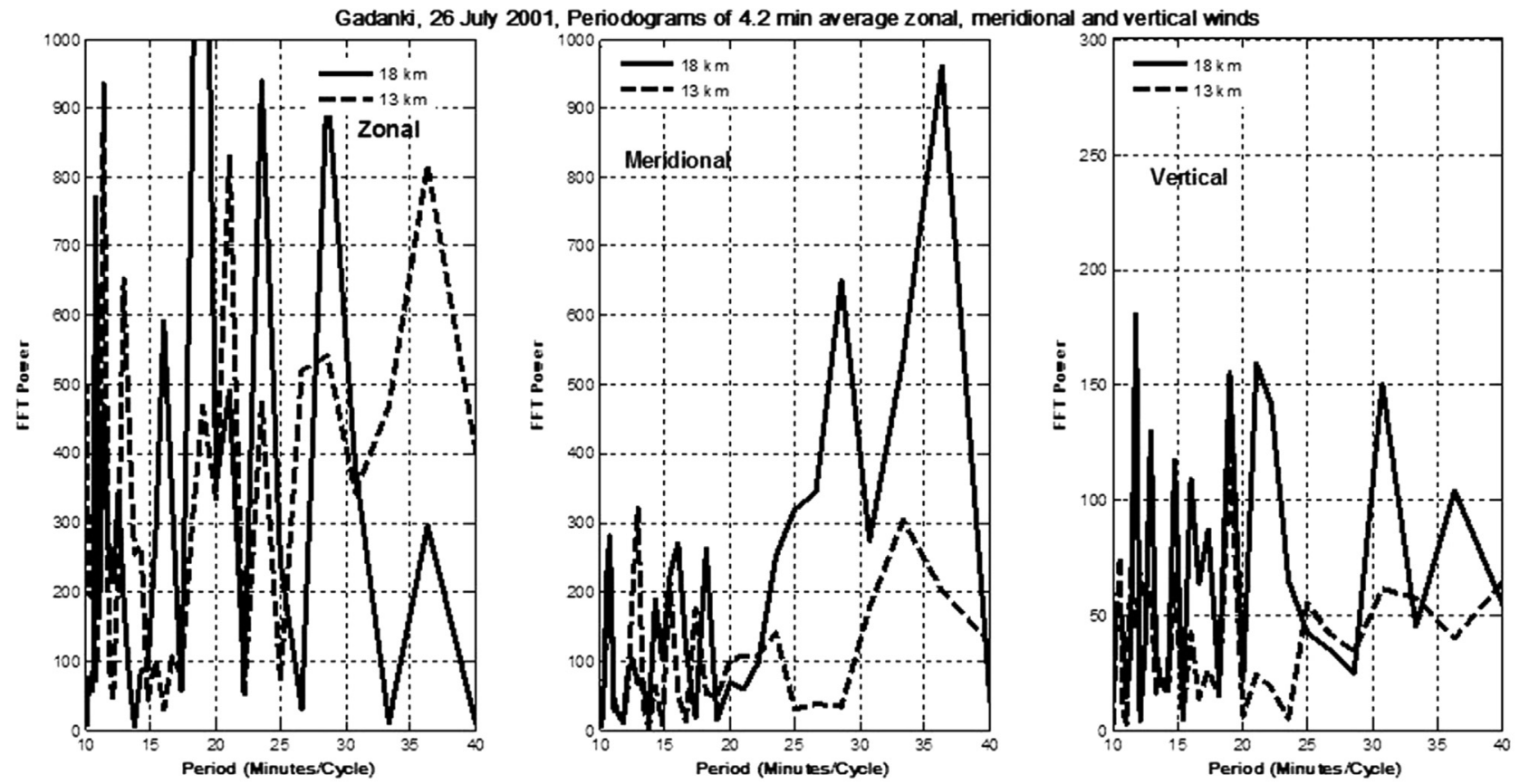

Fig. 11. Periodograms for $u, v, w$ at specific tropospheric heights on 26 July 2001.

calculated from these observational data are shown in Table 2. Further calculations based on these horizontal wavelength values and for the gravity wave periods between 10 and 30 min are given in Table 3. The results show that the phase and group velocities decrease with increase in wave periods from 10 to $30 \mathrm{~min}$ and increase with increasing vertical wavelengths. These characteristics are in accordance with the theoretical understanding of high speed gravity waves.

\section{Discussion}

While tropospheric weather system is dominated by mesoscale and synoptic scale perturbations $(\sim 100-1000 \mathrm{~km}$ range), the middle atmosphere dynamics is marked by the global scale general circulation (Orlanski, 1975; Watanabe et al., 2008). However due to the presence of higher atmospheric density and many energetic weather phenomena like deep convection, thunderstorms, solar heating etc., troposphere acts as the storehouse for generation of different types of waves which propagate upwards and transport momentum and energy in to the middle and upper atmosphere through the wave-mean flow interactions (Andrews and McIntyre, 1976). The Planetary, mixed Rossby-gravity and the Kelvin waves constitute one group of waves with periods from few days to weeks. The second group includes the solar thermal tides and gravity waves with periods varying from several minutes to $24 \mathrm{~h}$. The equatorial Kelvin and mixed Rossby gravity waves provide the easterly/westerly phases for the Quasi Biennial Oscillation
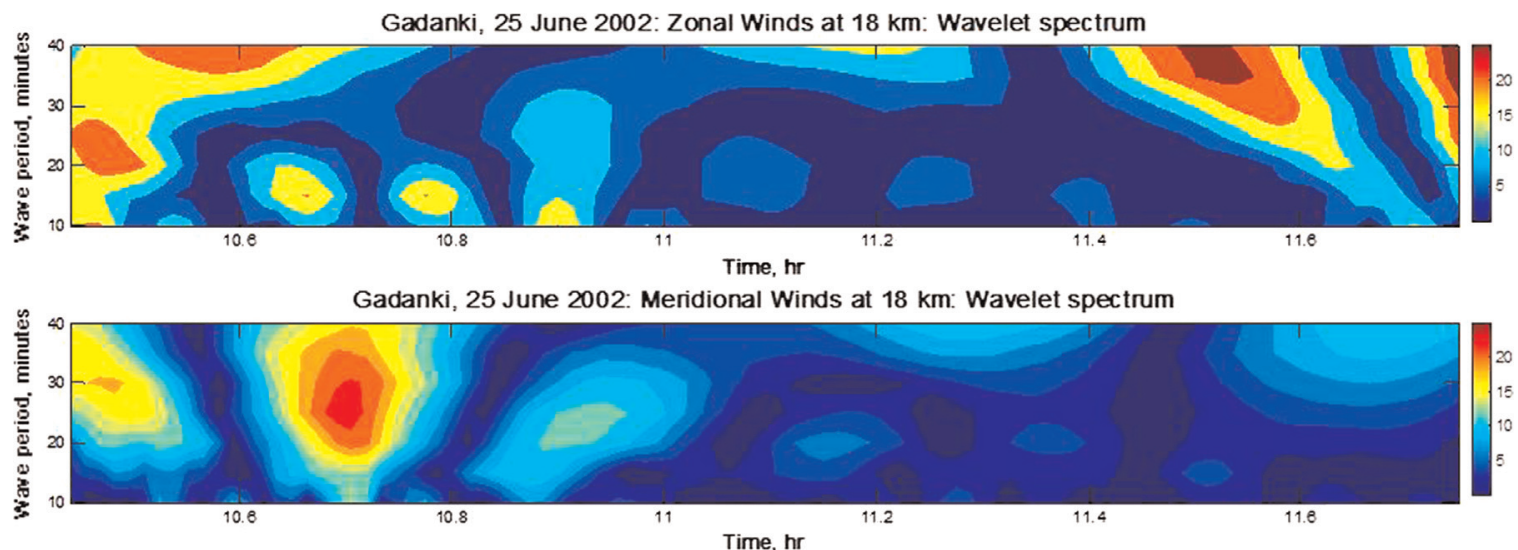

Gadanki, 25 June 2002: Vertical Winds at $18 \mathrm{~km}$ : Wavelet spectrum

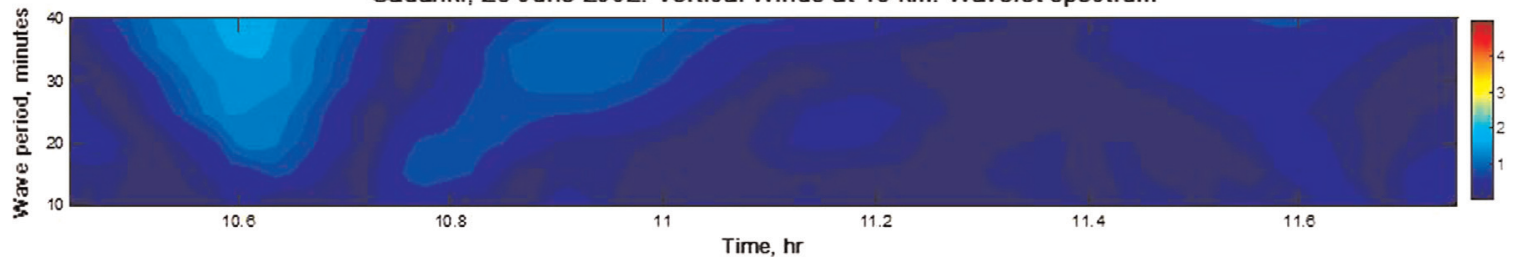

Fig. 12. Wavelet spectra of zonal, meridional and vertical winds at $18 \mathrm{~km}$ altitude on 25 June 2002. 
25 June 2002:Mesospheric SNR Contour (Zenith Beam)

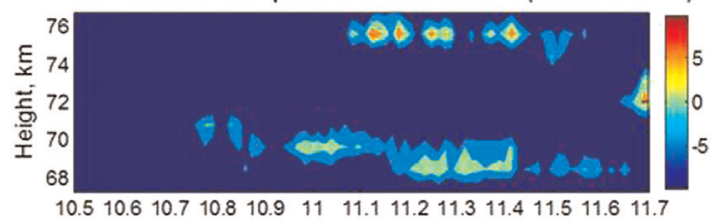

25 June 2002: Upper troposphere zonal velocity Contours

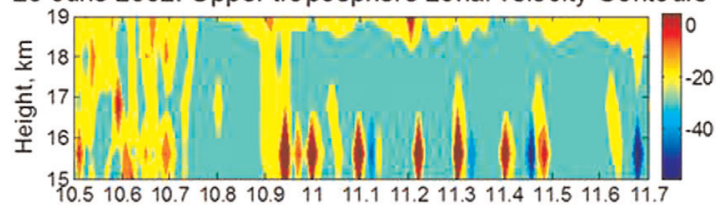

25 June 2002: $\mathrm{u}$ at $18 \mathrm{~km}$ wavelet spectrum

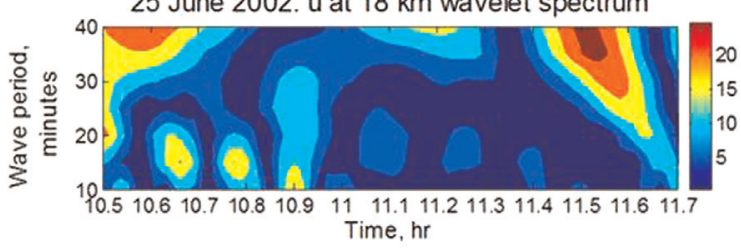

26 July 2001:Mesospheric SNR Contour (Zenith Beam)

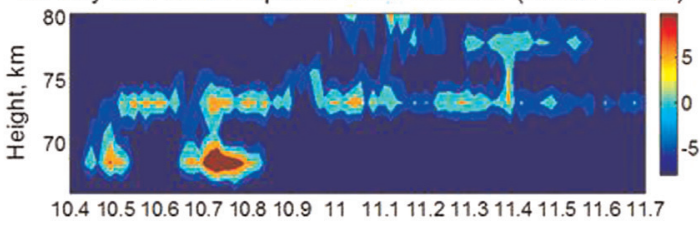

26 July 2001: Upper troposphere zonal velocity Contours

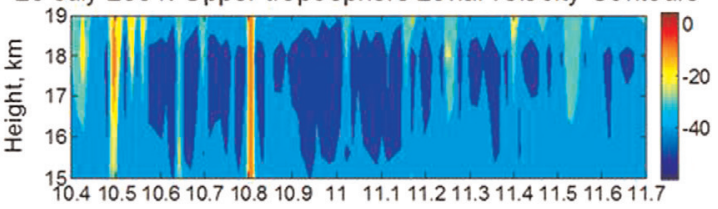

26 June 2001: $\mathrm{u}$ at $18 \mathrm{~km}$ wavelet spectrum

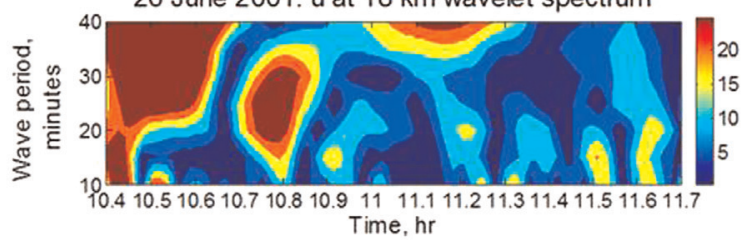

Fig. 13. A composite of gravity wave propagation effects into the mesosphere on 25 June 2002 and 26 July 2001.

(QBO) and the westerly phase for the Semi Annual Oscillation $(\mathrm{SAO})$ in the tropical middle atmospheric general circulation (Charney and Drazin, 1961; Holton, 1980). A detailed study was conducted on the variations of $\mathrm{QBO}$ and SAO through interactions of these equatorial waves over the Indian station Thumba $\left(8.5^{\circ} \mathrm{N}\right.$, $76.5^{\circ} \mathrm{E}$ ) using data from a large number of meteorological balloon and rocket soundings (Chakravarty et al., 1992). The tidal oscillations are forced by large scale solar heating of water vapour in the troposphere and ozone in the stratosphere. In tropics the latent heat release in convective systems forms a major heating source (Chapman and Lindzen, 1970). The amplitudes of these waves increase exponentially while propagating to the upper mesosphere/ lower thermosphere and finally break down after becoming convectively unstable and transfer easterly momentum to the mean flow. The diurnal and semi diurnal tides acquire large amplitudes around $100 \mathrm{~km}$ altitude (Forbes, 1984).

The atmospheric waves mainly result from maintaining an
Table 2

Computation of horizontal wavelengths of the gravity wave.

\begin{tabular}{lll}
\hline Vertical wavelength $(\mathrm{km})$ & $\begin{array}{l}\text { Wave amplitude }(\mathrm{m} / \\
\mathrm{s}) \\
\lambda_{\mathrm{z}}(=1 / \mathrm{m}) \text { (observed) }\end{array}$ & $\begin{array}{l}\text { Horizontal wavelength } \\
(\mathrm{km})\end{array}$ \\
\hline 5 & $20,1.2$ & $\begin{array}{l}w^{\prime} \text { (observed) } \\
\lambda_{\mathrm{h}}=-u^{\prime} /\left(m w^{\prime}\right) \text { (calculated) }\end{array}$ \\
10 & $20,1.2$ & 83 \\
20 & $20,1.2$ & 166 \\
5 & $10,1.2$ & 333 \\
10 & $10,1.2$ & 41 \\
20 & $10,1.2$ & 83 \\
\hline
\end{tabular}

Note: $m$ is vertical wave number, $\mathrm{u}^{\prime}$ and $\mathrm{w}^{\prime}$ are maximum wave amplitude for zonal and vertical velocities

equilibrium state between inertial and restoring forces acting on parcels of air. The gravity waves in a stratified and stable atmosphere are generated in the process when parcels of vertically

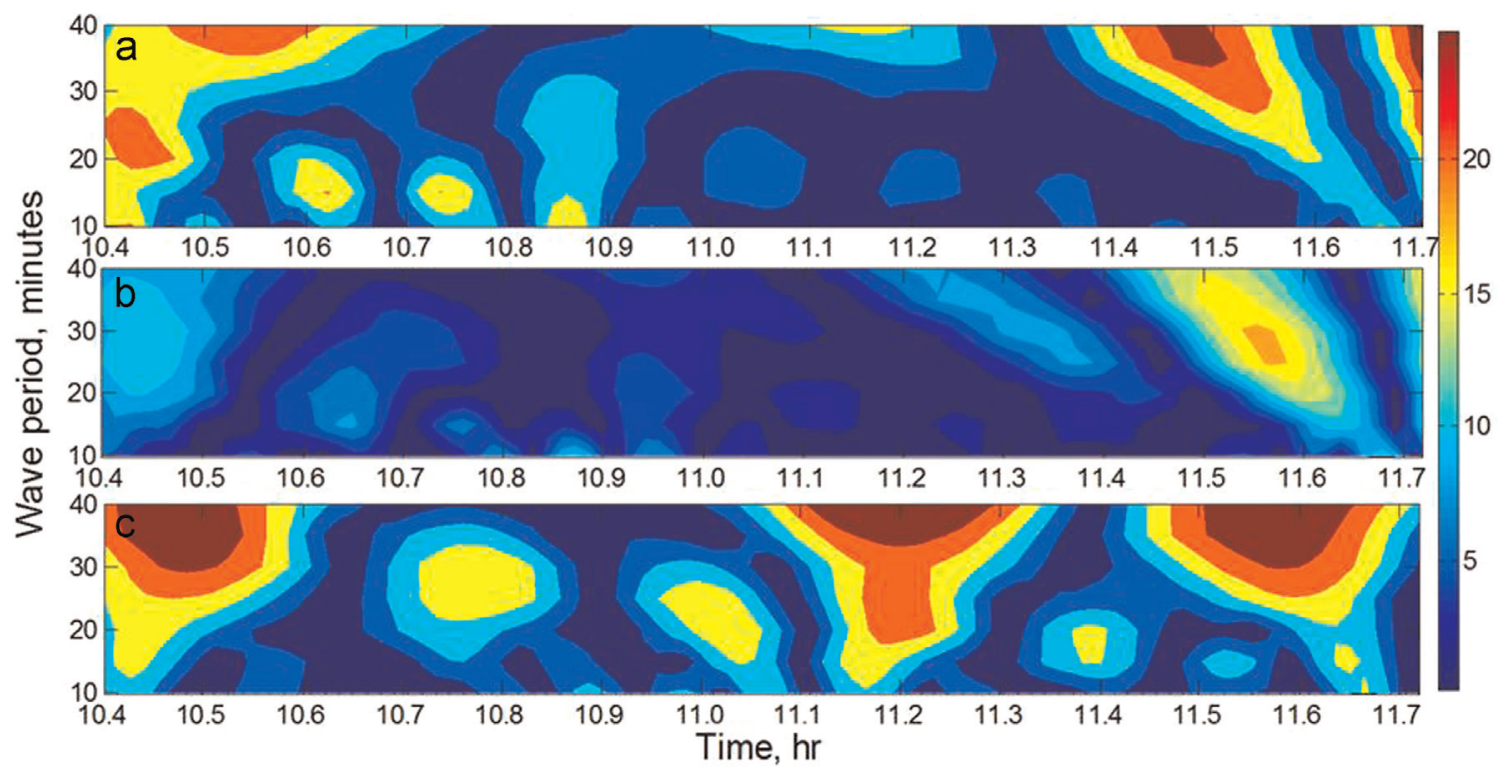

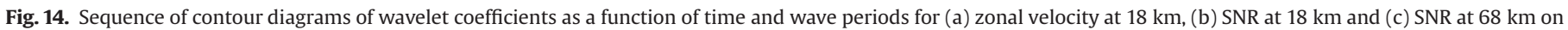
25 June 2002. 
Table 3

Computation of various parameters of gravity waves.

\begin{tabular}{|c|c|c|c|c|c|c|}
\hline Wave period (min) & $\lambda_{\mathrm{z}}(\mathrm{km})$ & $\lambda_{\mathrm{h}}(\mathrm{km})$ & $C_{\mathrm{ph}}(=\omega / k)(\mathrm{m} / \mathrm{s})$ & $C_{\mathrm{pz}}(=\omega / \mathrm{m})(\mathrm{m} / \mathrm{s})$ & $C_{\mathrm{gh}}=\left(N m^{2}\right) /\left(k^{2}+m^{2}\right)^{3 / 2}(\mathrm{~m} / \mathrm{s})$ & $C_{\mathrm{gz}}=(-N m k) /\left(k^{2}+m^{2}\right)^{3 / 2}(\mathrm{~m} / \mathrm{s})$ \\
\hline 10 & 5 & 83 & 138 & 8 & 16 & 1 \\
\hline 20 & 5 & 83 & 69 & 4 & 16 & 1 \\
\hline 30 & 5 & 83 & 46 & 3 & 16 & 1 \\
\hline 20 & 10 & 166 & 69 & 8 & 33 & 2 \\
\hline 20 & 20 & 333 & 277 & 16 & 66 & 4 \\
\hline
\end{tabular}

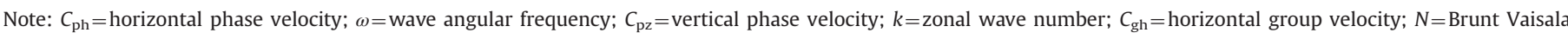
frequency; $C_{\mathrm{gz}}=$ vertical group velocity; $m=$ vertical wave number, $u^{\prime}$ and $w^{\prime}$ are maximum wave amplitudes for zonal and vertical directions.

displaced air regain the equilibrium condition (after being set to oscillate) through the force of gravity acting downwards and buoyancy acting upward. The gravity waves having frequencies lower than the natural Brunt Vaisala (BV) cut-off frequency have assumed great importance in recent times even if their role to understand the ionospheric irregularities at meteor ionisation heights $(\sim 80-110 \mathrm{~km})$ and also in $\mathrm{E}$ and $\mathrm{F}$ region ionosphere were pointed out very early by Hines (1960). Propagating up into the middle/upper atmosphere, the gravity wave amplitude increases exponentially to compensate the energy loss due to decrease in atmospheric density with height. In recent times there has been a renewed interest to study these gravity waves to understand the impacts not only on governing mesospheric and upper atmospheric processes but also the tropospheric weather and climate system because of their ubiquitous nature (Onishchenko et al., 2013).

In the present study the results of the signatures of small period (10-40 min) gravity waves in the troposphere and their subsequent propagation to the mesosphere are clearly demonstrated from the MST radar observations over the tropical Indian station. The gravity waves propagating up from tropopause heights grow in amplitude and reach the mesospheric heights, if the intervening winds do not act as a filter or result in the dissipation of gravity waves at critical levels The effect of the gravity waves propagating up from the UTLS region and causing perturbations/turbulence in the mesosphere can take place in two different ways. While the phase of these gravity waves propagates down with the wave phase velocity, their energy propagates up with the group velocity. The vertical phase velocities are 4-8 times higher than the vertical group velocities as shown in Table 3. Hence, the perturbation in the mesosphere first takes place due to the phase variation of the waves which sets the mesospheric electron density to vertical oscillations (without transfer of any momentum or energy to the medium) thus subjecting the medium to different values of electron-ion recombination coefficients which are temperature and hence height dependant. Due to this reason and the complex nature of the mesospheric dusty plasma processes, the turbulence layers of the mesosphere ( $\sim 2 \mathrm{~km}$ thick) get additional gradients in electron density distribution leading to enhanced radar reflectivity. The correlation shown by arrows in Fig. 2 would thus result from the phase propagation rather than the propagation of the group of waves. The momentum and energy are transported from e.g., the tropopause level to the mesospheric turbulence layer by the gravity wave propagation as given by their group velocities. The wave-mean flow interaction due to the momentum/energy transfer enhances the wind shear which finally breaks down into turbulence. This is the second and more delayed effect of enhanced turbulence and related modulation in mesospheric radar return signal strength. In the results presented here there would be a mix of these two phenomena depending on the development in the source region. The perturbation/turbulence structures in the mesospheric heights would first be detectable through the vertical propagation of the disturbance governed by the phase velocities of the gravity waves of individual wave modes rather than the propagation due to the group velocities of the wave packets. This explains the short time delay of $\sim 10-15 \mathrm{~min}$ for the gravity waves generated in the troposphere to reach the mesospheric heights.

In the present study, the observed vertical profiles of the zonal and vertical winds have been utilised to estimate the $\lambda_{z}$ values which range between 5 and $20 \mathrm{~km}$. The derived wave parameters based on these $\lambda_{z}$ values show large variations with wave periods. The large differences between the $C_{\mathrm{ph}}$ and $C_{\mathrm{gh}}$ values or large values of $C_{\mathrm{ph}}$ thus occur for short periods of time as extreme cases particularly when $\lambda_{\mathrm{z}}$ values are close to $20 \mathrm{~km}$ or more. For rest of the wave modes shown in Table 3, the results fall into the overall schemes mentioned by others (e.g., Chang-Ming et al., 2000).

The gravity waves which are generated in the lower troposphere cannot be easily detected in the velocity fields of the troposphere as the amplitudes are small compared to variations due to the turbulence itself. However as these waves increase in amplitude while propagating up, their impressions can be clearly detected in the velocity fields near the tropopause. While the wave intensities as determined from zonal velocity fields are strong enough at tropopause level, the SNR at tropopause level obtained from the radar backscattered data shows marginal wave related effects even at tropopause level. When these waves propagate further up to the mesosphere they become the major energy source for the radar backscatter and here the SNR strongly reflects the undulations due to the gravity waves with certain time delays compared to the waves at tropopause heights. A clear example of this phenomenon is shown in Fig. 14 where the spectra of wavelet coefficients for 10-40 min period gravity waves are presented for (a) zonal winds at $18 \mathrm{~km}$ tropopause height, (b) SNR from $18 \mathrm{~km}$ scattering layer and (c) SNR from $68 \mathrm{~km}$ scattering layer on 25 June 2002. This result has a potential for application in tracing weak/ undetectable tropospheric weather systems of convection, thunderstorms etc., by observing the mesospheric radar signal variation patterns particularly during the SW and NE monsoon periods. As mentioned above, from the calculation of the wave parameters at the tropopause level, the basic characteristics of the vertically propagating gravity waves have been derived. The vertical and horizontal wavelength values and also the phase and group velocities determined for different wave periods indicate that these gravity waves have very high speeds. Hence, if these are not filtered by the critical levels in the intervening passage, they could reach the mesospheric heights in a short time. However, further work would need to be done using additional data for a detailed assessment of the gravity wave detectability and impacts before the mesospheric observations could be used with advantage. In order that the gravity waves are monitored closely over the tropics, the efforts being made by various groups in India and elsewhere for setting up networks of ST radars for weather and climate related studies, could consider ensuring adequate sensitivity of at least a few of these radars for continuous observation to cover the lower mesospheric region also. 


\section{Conclusions}

The findings of the investigations (from a selection of two days of data of a special campaign dedicated to the simultaneous measurement of the fluctuations in the UTLS and in the mesosphere during 2001 and one days data from a follow up observation in 2002) using the Indian MST radar are summarised below.

1. The time-height sections of the signal strength (SNR) observed using the MST radar facility at Gadanki $\left(13.5^{\circ} \mathrm{N}, 79.2^{\circ} \mathrm{E}\right)$ during day time of 25 June 2002 show at least 3 distinct layers of intense and continuous backscatter in the troposphere and at least two scattering layers between 65 and $75 \mathrm{~km}$ in the mesosphere. The thickness of these horizontally stratified layers varies from 4 to $5 \mathrm{~km}$ in the troposphere to about $2-3 \mathrm{~km}$ in the mesosphere.

2. The FFT analysis of the zonal wind velocity fields $(u)$ at the 3 troposphere levels of 8,13 and $18 \mathrm{~km}$ shows the presence of gravity waves with several peaks between periods of 10-40 min and maximum wave amplitudes near the tropopause. Even if it is difficult to compute velocity fields in the mesosphere, the continuity of these vertically propagating gravity waves has been confirmed by analysing and subjecting the SNR time series of mesospheric scattering layer to wavelet analysis.

3. The wavelet spectral coefficients derived from the time series of SNR around the mesospheric scattering layer show clear presence of gravity waves with periods between 10 and $40 \mathrm{~min}$ with varied strengths which are well correlated with the spectral characteristics of the gravity waves observed in the zonal velocity field at tropopause level. The wavelet coefficients due to the effect of these gravity waves in the time series of SNR at tropopause level is less pronounced compared to those in the mesosphere. This indicates that the velocity fields in tropopause level and SNR field in the mesospheric level provide a better data-set for such studies in absence of wind velocity field data in the mesosphere which is difficult to obtain due to asymmetry and inhomogeneity in the distribution of turbulent scattering centres.

4. The characteristics of the gravity waves have been determined by calculating the wave parameters using the observations presented here. The phase and group velocity components for different wave periods have been computed and the effect of changing the vertical wavelengths has been brought out. It is noted from these parameters that these gravity waves have high horizontal phase speeds for smaller wave periods. Relatively high frequency (periods $<1 \mathrm{~h}$ ) gravity waves which can be generated from locations close (within $300-500 \mathrm{~km}$ ) to the radar station would have prominent effects in producing tropopause wind velocity and mesospheric SNR fluctuations. The vertically propagating gravity waves would set the scattering ionisation irregularities into oscillation to encounter electronion recombination coefficients varying with height. This would result in transferring the wave characteristics to the turbulent scatter. In addition the component of the group velocity of these gravity waves in the zonal wind direction would transfer momentum and accelerate the background wind leading to increasing wind shears which could break down at critical levels to generate more ionisation irregularities. Both these phenomena would result in gravity wave perturbation of the mesospheric scattering layer(s) and get reflected in the mesospheric radar backscatter signal and SNR.

5. The direct coupling of the tropospheric and mesospheric phenomena through the vertically propagating gravity waves over a tropical station presented in this paper has important implications from the view-point of improving our understanding of the ubiquitous and monsoon convective system related gravity wave induced dynamics of the complex mesospheric plasma acting like tracers and detectable by MST radars. Such troposphere-mesosphere linked results being quite rare, more such integrated analysis on the propagation of the gravity waves should be carried out for better quantification of the phenomenon.

\section{Acknowledgement}

The authors thank the Director, National Atmospheric Research Laboratory (NARL), Gadanki, India for providing the MST radar data used in the present study. The author wishes to thank Dr. V. K. Anandan of ISRO Telemetry Tracking and Command Network (ISTRAC), Bangalore for making the latest version of ADP (Atmospheric Data Processor) available for MST radar data analysis. The authors would like to thank the reviewers for their constructive suggestions and critical comments that helped in improving the paper.

\section{Appendix A. Supplementary material}

Supplementary data associated with this article can be found in the online version at http://dx.doi.org/.10.1016/j.jastp.2015.07.013.

\section{References}

Anandan, V.K., Balamuralidhar, P., Rao, P.B., Jain, A.R., Jain, C.J., 2005. An adaptive moments estimation technique applied to mst radar echoes. J. Atmos. Ocean. Technol. 22, 396-408 2005.

Andrews, D.G., McIntyre, M.E., 1976. Planetary waves in horizontal and vertical shear: the generalized Eliassen-Palm relation and the mean zonal acceleration. J. Atmos. Sci. 33, 2031-2048

Balsley, B.B., Gage, K.S., 1980. The MST radar technique: potential for middle atmospheric studies. Pure Appl. Geophys. 118, 452-493.

Lee, C.F., Vaughan, G., Hooper, D.A., 2014. Evaluation of wind profiles from the NERC MST radar, Aberystwyth. Atmos. Meas. Tech. 7, 3113-3126.

Chakravarty, S.C., Datta, J., 2007. Mesospheric backscatter echoes as observed by the Indian MST radar facility at Gadanki. India J. Radio Space Phys. 36, 489-501.

Chakravarty, S.C., Datta, J., Kamala, S., Gupta, S.P., 2004. High resolution mesospheric layer structures from MST radar backscatter echoes over low latitude. J. Atmos. Sol. Terr. Phys. 66, 859-866.

Chakravarty, S.C., Datta, Jayati, Revankar, C.P., 1992. Climatology of long-period oscillations in the equatorial middle atmosphere over Thumba. India Curr. Sci. $63,33-42$.

Chakravarty, S.C., 2012. Gravity wave propagation studies using the Indian MST radar observations. Adv. Space Res. 49, 716-724.

Chang-Ming, F., Molinaro, F., Leveau, J., Keckhut, P., Hauchecorne, A., 2000. Analysis of gravity waves in the tropical middle atmosphere over La Reunion Island $\left(21^{\circ} \mathrm{S}, 55^{\circ} \mathrm{E}\right)$ with lidar using wavelet techniques. Ann. Geophys. 18, 485-498.

Chapman, S., Lindzen, R.S., 1970. Atmospheric Tides. D. Reidel Press, Dordrecht, Holland.

Charney, J.G., Drazin, P.G., 1961. Propagation of planetary-scale disturbances from the lower into the upper atmosphere. J. Geophys. Res. 66, 83-109.

Chilson, P., Kirkwood, S., Nilsson, A., 1999. The Esrange MST radar: a brief introduction and procedure for range validation using balloons. Radio Sci. 34, 427-463.

Das, S.S., Jain, A.R., Kishore Kumar, K., Narayana Rao, D., 2008. Diurnal variability of the tropical tropopause: significance of VHF radar measurements. Radio Sci. 43, RS6003. http://dx.doi.org/10.1029/2008RS003824.

Datta, J., Chakravarty, S.C., Prasad, B.S.N., 2001. Indian MST radar - Mesospheric studies. Curr. Sci. 81, 661-666.

Fritts, C.David, Alexander, M.Joan, 2003. Gravity wave dynamics and effects in the middle atmosphere. Rev. Geophys. 41, 1003-1067.

Hines, C.O., 1960. Internal atmospheric gravity waves at ionospheric heights. Can. J. Phys. 38, 1441-1481.

Holton, J.R., 1980. Wave propagation and transport in the middle atmosphere. Philos. Trans. R. Soc. Lond.: Math. Phys. Sci. 296, 73-85.

Forbes, M., Jeffrey, 1984. Middle atmosphere tides. J. Atmos. Terr. Phys. 46, 1049-1067.

Kamala, S., Rao., D. Narayana, Chakravarty, S.C., Datta, J., Prasad, B.S.N., 2003. Vertical structure of mesospheric echoes from the Indian MST radar. J. Atmos. Solar Terr. Phys 65, 71-83.

Kubo, K., Sugiyama, T., Nakamura, T., Fukao, S., 1997. Seasonal and inter-annual variability of mesospheric echoes observed with the middle and upper 
Atmosphere radar during 1986-1995. Geophys. Res. Lett. 24, 1211.

Onishchenko, O., Pokhotelov, O., Fedun, V., 2013. Convective cells of internal gravity waves in the earth's atmosphere with finite temperature gradient. Ann. Geophys. $31,459-462$.

Orlanski, Isidoro, 1975. A rational subdivision of scales for atmospheric processes. Bull. Am. Meteorol. Soc. 56, 527-530.

Patra, A.K., Rao, P.B., Anandan, V.K., Jain, A.R., 1997. Radar observations of 2.8 m equatorial spread F irregularities. J. Atmos. Sol. Terr. Phys. 59, 1633-1641.

Pramitha, M., Venkat Ratnam, M., Taori, A., Krishna Murthy, B.V., Pallamraju, D. Vijaya Bhaskar Rao, S., 2015. Evidence for tropospheric wind shear excitation of high phase speed gravity waves reaching the mesosphere using the ray tracing technique. Atmos. Chem. Phys. 15, 2709-2721. http://dx.doi.org/10.5194/ acp1527092015.
Rao, P.B., Jain, A.R., Kishore, P., Balamuralidhar, P., Damle, S.H., Viswanathan, G., 1995. Indian MST radar 1, system description and sample vector wind measurements in ST mode. Radio Sci. 30, 1125-1138.

Röttger, J., 1980. Reflection and scattering of VHF radar signals from atmospheric refractivity structures. Radio Sci. 15, 259-276. http://dx.doi.org/10.1029/ RS015i002p00259.

Tsuda, T., 2014. Characteristics of atmospheric gravity waves observed using the MU (Middle and Upper atmosphere) radar and GPS (Global Positioning System) radio occultation. Proc. Jpn. Acad. Ser. B 90, 12-27.

Watanabe, Shingo, Kawatani, Yoshio, Tomikawa, Yoshihiro, Miyazaki, Kazuyuki, Takahashi, Masaaki, Sato, Kaoru, 2008. General aspects of a T213L256 middle atmosphere general circulation model. J. Geophys. Res. 113, D12110. http://dx. doi.org/10.1029/2008JD010026. 